20

\title{
Исследование интернализации контейнеров с антимикотиком клетками фибробластов методами визуализирующей проточной цитометрии и конфокальной лазерной сканирующей микроскопии
}

\author{
(С) Р.А. Верховский, Е.В. Ленгерт, М.С. Савельева, А.А. Козлова, В.В. Тучин, Ю.И. Свенская \\ Саратовский национальный исследовательский государственный университет им. Н.Г. Чернышевского, \\ 410012 Саратов, Россия \\ e-mail: r.a.verhovskiy@mail.ru, svenskaya@info.sgu.ru
}

Поступила в редакцию 12.12.2019 г.

В окончательной редакции 27.01.2020 г.

Принята к публикации 28.02.2020 г.

\begin{abstract}
Разработка и оптимизация систем адресной доставки лекарственных веществ является активно развивающимся направлением фармацевтики. К важным свойствам, предъявляемым к разрабатываемым контейнерамносителям, относится не только возможность доставки, высвобождения и локализации иммобилизованного терапевтического агента в зоне патологического изменения, но и безопасность применения для организма. Интернализация является одним из косвенных доказательств биосовместимости носителей, содержащих терапевтический агент, поскольку отражает результат их взаимодействия с клеткой. Сохранение жизнеспособности клетки после проникновения носителя внутрь свидетельствует о его безопасности. Таким образом, оценка эффективности захвата носителей различными клеточными линиями позволяет получить информацию об их биосовместимости. Конфокальная лазерная сканирующая микроскопия рутинно применяется для решения данной задачи. Однако такой метод обладает рядом недостатков, в числе которых высокая трудои времязатратность, не позволяющая получить большой массив данных в короткие сроки. Классические системы проточной цитофлуориметрии также широко применяются для оценки цитотоксичности и позволяют проанализировать до нескольких тысяч объектов в секунду. Однако подобные системы, в отличие от конфокальных лазерных сканирующих микроскопов, не позволяют получать изображения объектов и, как следствие, верифицировать полученные данные. Новое поколение проточных цитометров объединило в себе сильные стороны вышеупомянутых методов. Так, существующие на сегодняшний день системы проточной цитометрии с возможностью визуализации позволяют анализировать порядка 5000 объектов в секунду, предоставляя при этом их флуоресцентные и светлопольные изображения. Однако стоит отметить, что применение гидродинамической фокусировки объектов в фокальной области объектива, используемого для визуализации, не исключает возможности их флуктуаций в потоке и, как следствие, не позволяет сделать однозначный вывод о локализации носителей в пределах клетки. Кроме того, анализ интернализации носителей, обеспечивающих пролонгированную доставку лекарственного средства, при использовании данного метода затруднен по причине накопления высвобождаемого из носителя флуоресцентно меченного препарата в эндосомах клетки. Для решения данной проблемы нами была проведена оптимизация протокола оценки частиц методом визуализирующей проточной цитофлуориметрии. Изучался захват субмикронных частиц ватерита клетками дермальных фибробластов мыши. Сравнительное исследование захвата частиц клетками с помощью методов конфокальной лазерной сканирующей микроскопии и визуализирующей проточной цитофлуориметрии продемонстрировало отличную корреляцию полученных данных. Высокая пропускная способность метода проточной цитометрии в сочетании с оптимизированным алгоритмом анализа по определению локализации частиц в клетке позволяет осуществлять быструю оценку качества интернализации исследуемого образца.
\end{abstract}

Ключевые слова: визуализирующая проточная цитофлуориметрия, конфокальная лазерная сканирующая микроскопия, адресная доставка лекарств, субмикронные контейнеры-носители, оценка интернализации частиц клетками.

DOI: $10.21883 /$ OS.2020.06.49413.26-20

\section{Введение}

Одним из активно развивающихся направлений современной фармацевтики является разработка новых методов доставки лекарственных средств (ЛС). Исследование безопасности и биосовместимости подобных систем является неотъемлемым этапом их разработки. На сегодняшний день существует множество методов, позволяющих прямо (путем селективного окрашивания живых [1] либо мертвых [2,3] клеток) или косвенно (путем определения их метаболической активности $[4,5])$ оценивать цитотоксичность носителей ЛС. В результате взаимодействия клетки и носителя возможна либо его адсорбция на поверхность клеточной мембраны, либо проникновение (интернализация) внутрь клетки. Сохранение жизнеспособности клетки после интернализации носителя свидетельствует о его безопасности. 
Также немаловажную роль при выборе контейнера для ЛС играют такие параметры, как простота и масштабируемость методики его изготовления, низкая себестоимость конечного продукта. Перспективными с точки зрения совокупности данных свойств являются частицы ватерита, представляющие собой одну из полиморфных модификаций карбоната кальция [6]. Пористая структура таких носителей позволяет иммобилизовать внутрь частицы широкий спектр биологически активных веществ, таких как белки [7-10], ферменты [11-13], нуклеиновые кислоты $[14,15]$, квантовые точки [16,17], наночастицы металлов [18-22], пептиды [23,24], а также различные лекарственные препараты [25-31]. Процесс растворения частицы ватерита и ее перекристаллизации в кальцит сопровождается высвобождением загруженного вещества. Скорость протекания данного процесса напрямую зависит от свойств среды $[25,28,30,32]$. При этом нанесение на поверхность частицы слоя полимера позволяет замедлить высвобождение лекарственного средства ввиду снижения скорости перекристаллизации $[11,20]$. Было показано, что частицы карбоната кальция легко могут быть захвачены клетками, не оказывая при этом выраженного токсического эффекта [28,33,34], и, как следствие, могут быть использованы для внутриклеточной доставки ЛС.

Основным методом, применяемым для оценки интернализации, является конфокальная лазерная сканирующая микроскопия (КЛСМ) [35,36]. Данный метод позволяет точно определять локализацию носителя внутри клетки благодаря возможности ее сканирования по осям $X, Y$ и $Z$ [36-38]. Однако процесс 3D-сканирования клетки трудоемок и не лучшим образом подходит для набора статистики.

Метод проточной цитофлуориметрии, в свою очередь, позволяет получить гораздо больший объем данных за достаточно короткий промежуток времени. Классические системы проточной цитофлуориметрии широко применяются для оценки цитотоксичности [39,40]. Высокая пропускная способность данного метода позволяет анализировать до нескольких тысяч объектов в секунду. Однако в отличие от КЛСМ данный подход не позволяет получать изображения исследуемых объектов и, как следствие, верифицировать полученные данные.

Новое поколение проточных цитометров с возможностью визуализации объединяет в себе главные преимущества вышеупомянутых методов. Современные проточные цитофлуориметры способны получать и анализировать светлопольные и флуоресцентные изображения 5000 объектов в секунду. Это достигается благодаря применению гидродинамической фокусировки объектов в фокальной области объектива, применяемого для их визуализации. Подобный функционал обеспечивает применение таких цитофлуориметров для решения целого ряда задач, в том числе и для оценки интернализации [41]. Однако применение гидродинамической фокусировки не исключает возможности колебания объектов в потоке, что в свою очередь не позволяет сделать однозначный вывод о локализации носителей в пределах клетки.

Помимо этого, данный метод не лучшим образом подходит для анализа интернализации носителей, обеспечивающих пролонгированный эффект. В этом случае возможно преждевременное высвобождение красителя, моделирующего ЛС, в объем эндосомы.

В настоящей работе проведено сравнительное исследование двух подходов, применяемых для оценки интернализации. Методами КЛСМ и визуализирующей проточной цитометрии (ВПЦ) произведен анализ интернализации фибробластами мыши ряда носителей, выполненных на основе частиц ватерита, нагруженных противогрибковым препаратом, с различной структурой оболочки. На основании полученных данных был сделан вывод об эффективности использования вышеупомянутых подходов для изучения интернализации субмикронных ватеритных носителей.

\section{Материалы и методы}

\section{Синтез контейнеров, содержащих антимикотик}

Формирование субмикронных частиц ватерита, содержащих антимикотик, осуществлялось путем совместного осаждения противогрибкового препарата „Гризеофульвин“ (Sigma-Aldrich, США) в процессе их формирования в среде этиленгликоля (Sigma-Aldrich, США) [28,29]. Для этого был приготовлен раствор гризеофульвина в этиленгликоле концентрацией $2 \mathrm{mg} / \mathrm{mL}$. С целью повышения эффективности растворения антимикотика полученную смесь подвергали обработке в ультразвуковой ванне (Сапфир, Россия) с частотой $35 \mathrm{kHz}$ и плотностью мощности $0.64 \mathrm{~W} / \mathrm{cm}^{2}$ в течение $1 \mathrm{~h}$ при $50^{\circ} \mathrm{C}$. Одинаковые объемы $1 \mathrm{M}$ водных растворов дигидрата хлорида кальция и карбоната натрия (Sigma-Aldrich, США) смешивали с полученным раствором антимикотика в соотношении $1: 5$, а затем между собой. Процесс смешивания растворов проводили на магнитной мешалке со скоростью $700 \mathrm{rpm}$ в течение $2.5 \mathrm{~h}$ при температуре $25-30^{\circ} \mathrm{C}$. Осаждение микрочастиц было проведено при скорости $5000 \mathrm{rpm}$ в течение $10 \mathrm{~min}$. Была проведена трехкратная промывка контейнеров водой и однократная 95\% этиловым спиртом с целью их отмывки от этиленгликоля и излишка солей. Затем образец высушивали при температуре $60^{\circ} \mathrm{C}$ в течение $1 \mathrm{~h}$.

\section{Оценка эффективности загрузки антимикотика в контейнеры}

Количественная оценка эффективности загрузки антимикотика в носители осуществлялась путем измерения спектров флуоресценции растворов на приборе Synergy H1 (BioTek, CША). Регистрация спектров флуоресценции осуществлялась в диапазоне 319-500 nm при возбуждении излучением с длиной волны $292 \mathrm{~nm}$. 

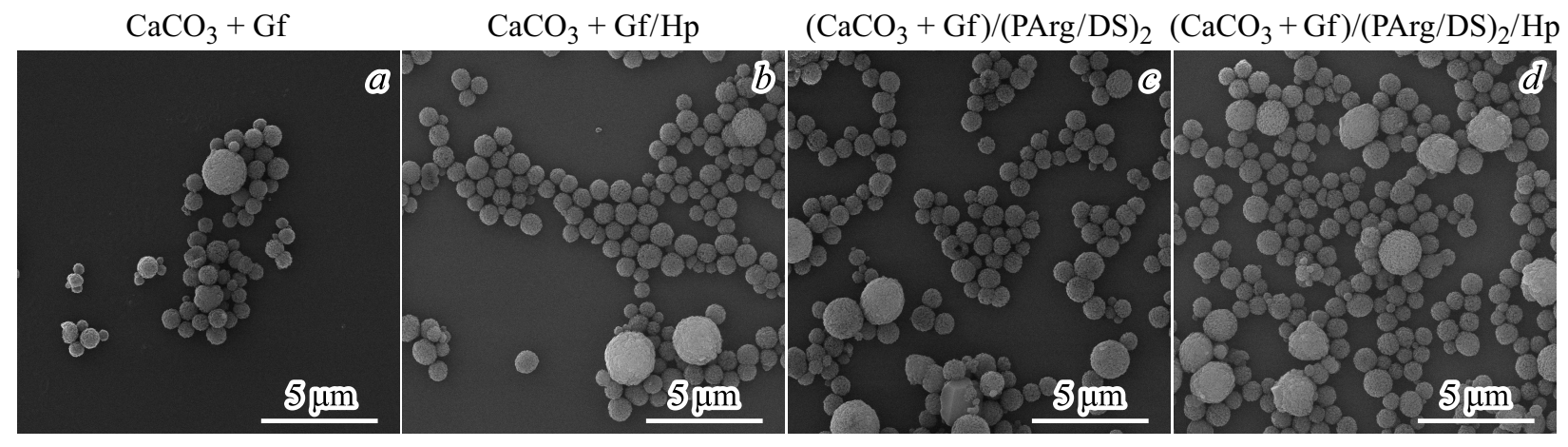

Рис. 1. СЭМ-изображения ватеритных контейнеров $\left(\mathrm{CaCO}_{3}\right)$, содержащих антимикотик „Гризеофульвин“ Gf: без оболочки (a), покрытых слоем гепарина Нp $(b)$, двумя бислоями полиэлектролитов PArg/DS $(c)$, а также двумя бислоями полиэлектролитов и гепарином $(d)$.

Для построения калибровочной кривой были получены спектры флуоресценции различных концентраций препарата „Гризеофульвин“ в этаноле и этиленгликоле.

Для оценки эффективности загрузки частиц ватерита с гризеофульвином были измерены надосадочные жидкости, отобранные после синтеза и промывки частиц. Полученные значения флуоресценции для каждого супернатанта были соотнесены с калибровочными кривыми, что позволило рассчитать концентрацию препарата, оставшегося в растворе. Масса препарата, иммобилизованного в ватеритную матрицу, была рассчитана по методике, описанной нами ранее [30].

По результатам исследований эффективность загрузки гризеофульвина в пористые частицы карбоната кальция методом соосаждения составила $20 \%$.

\section{Адсорбция флуоресцентного красителя на поверхность контейнеров, содержащих антимикотик}

С целью дальнейшей визуализации полученных контейнеров оптическими методами была осуществлена их модификация модельным флуоресцентным красителем. Для этого на поверхность синтезированных частиц карбоната кальция, содержащих гризеофульвин, был адсорбирован слой бычьего сывороточного альбумина, конъюгированного с флуоресцентным красителем тетрасульфородамином (TRITC-BSA). Для этого высушенные контейнеры помещались в водный раствор TRITC-BSA концентрацией $2.5 \mathrm{mg} / \mathrm{mL}$ на $30 \mathrm{~min}$ при непрерывном перемешивании. После завершения процесса адсорбции осадок промывался водой и далее использовался для нанесения полиэлектролитных слоев.

\section{Модификация поверхности полученных контейнеров}

Поверхность частиц ватерита $\left(\mathrm{CaCO}_{3}\right)$, содержащих антимикотик „Гризеофульвин“ (Gf) и меченых TRITCBSA, была модифицирована биосовместимыми биодеградируемыми полиэлектролитами полиаргинином (PArg) и сульфатомдекстрана (DS) (Sigma-Aldrich, США), а также антикоагулянтом - гепарином (Нp) для формирования мультислойных оболочек с различным числом слоев (от одного до пяти). Формирование оболочек было проведено методом послойной адсорбции на поверхность ватеритных контейнеров [42]. В результате были получены следующие образцы: контейнеры с оболочкой антикоагулянта: $\left(\mathrm{CaCO}_{3}+\mathrm{Gf}\right) / \mathrm{Hp}$; контейнеры с двумя бислоями полиэлектролитов $\left(\mathrm{CaCO}_{3}+\mathrm{Gf}\right) /(\mathrm{PArg} / \mathrm{DS})_{2}$; контейнеры с двумя бислоями полиэлектролитов и слоем антикоагулянта $\left(\mathrm{CaCO}_{3}+\mathrm{Gf}\right) /(\mathrm{PArg} / \mathrm{DS})_{2} / \mathrm{Hp}$.

Морфология полученных образцов была исследована методом сканирующей электронной микроскопии (CЭM) MIRA II LMU (Tescan, Чехия) при рабочем напряжении $30 \mathrm{kV}$. Результаты представлены на рис. 1.

\section{Оптимизация протокола инкубации полученных контейнеров с клетками фибробластов}

Влияние полиэлектролитной оболочки на эффективность интернализации полученных контейнеров было исследовано на культуре клеток фибробластов мыши (L929). C целью определения длительности инкубации частиц с клетками фибробластов, при которой обеспечивается наиболее эффективный захват частиц клетками, была проведена серия экспериментов.

Клеточную линию L929 выращивали на питательной среде DMEM/F12 с L-глутамином (БиолоT, Россия) и добавлением 10\% эмбриональной бычьей сыворотки FBS (ThermoFisher, США), а также 1\% смеси антибиотиков пенициллина и стрептомицина (ThermoFisher, США) в инкубаторе с увлажненной средой при $37^{\circ} \mathrm{C}$ и $5 \%$ содержании $\mathrm{CO}_{2}$ в газовой среде. Питательную среду заменяли каждые три дня. После образования монослоя клетки снимали с культурального флакона раствором трипсина и ЭДТА $(0.25 \%$ трипсина и $0.02 \%$ ЭДТА) (ThermoFisher, США) и подсчитывали с помощью автоматического счетчика клеток Countess (Invitrogen, США).

Суспензию клеток в количестве $5 \cdot 10^{5}$ помещали в чашку Петри диаметром $35 \mathrm{~mm}$ и культивировали в течение ночи, чтобы обеспечить прикрепление клеток 

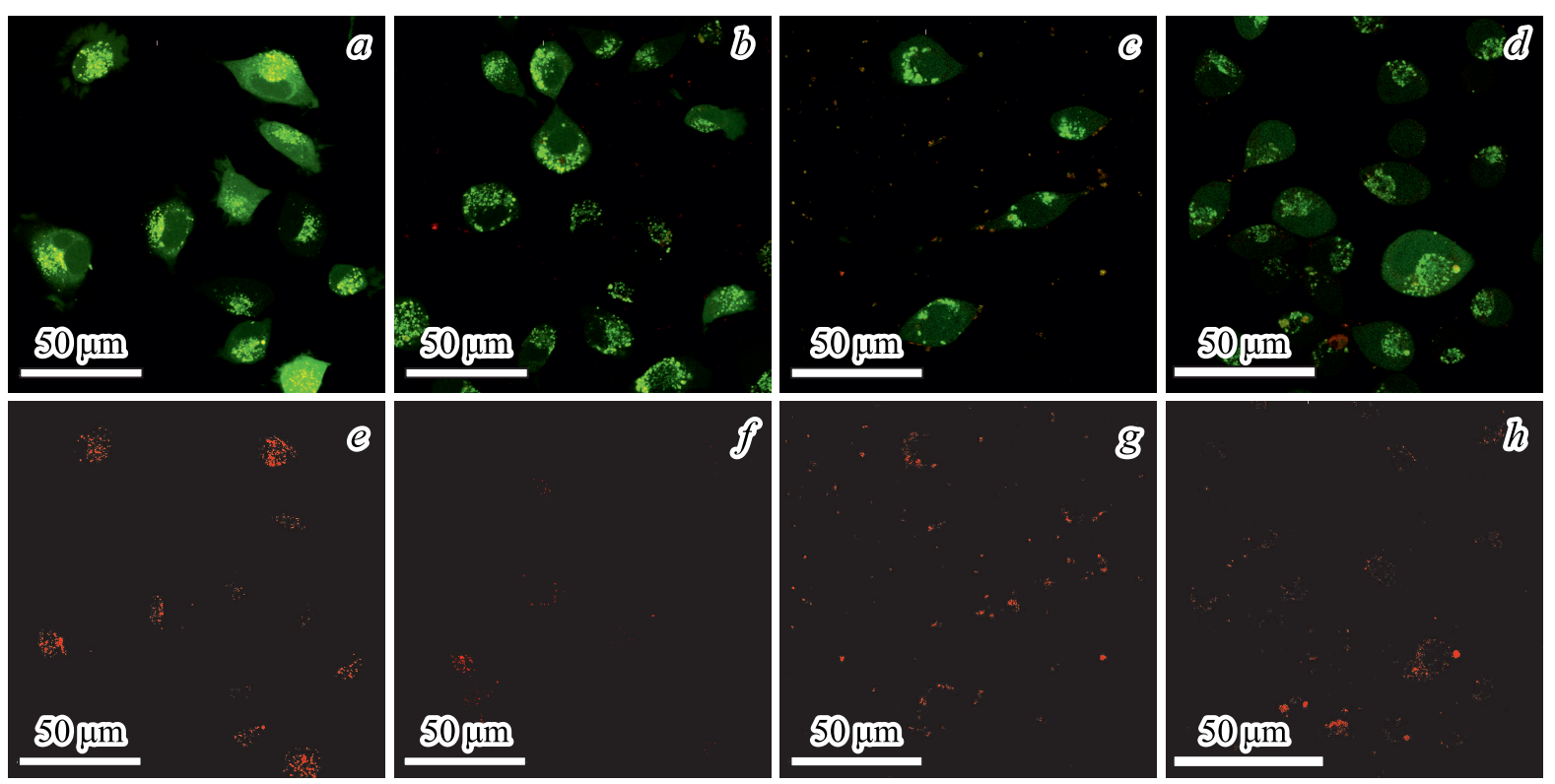

Рис. 2. Изображения, полученные методом КЛСМ, клеток фибробластов мыши L929, окрашенных красителем Сalcein AM: до $(a, e)$ инкубации, через $4 \mathrm{~h}(b, f)$, через $8 \mathrm{~h}(c, g)$, через $15 \mathrm{~h}$ после инкубации с частицами ватерита, окрашенными флуоресцентным красителем TRITC-BSA $(d, h)$. Изображения верхнего ряда представляют собой наложения зеленого и красного флуоресцентных каналов. Изображения нижнего ряда представляют флуоресценцию в красном канале.

к культуральному пластику. После этого к клеткам добавляли частицы ватерита, содержащие антимикотик и флуоресцентный краситель, в количестве 10 частиц на клетку и инкубировали в течение 4,8 и $15 \mathrm{~h}$. Затем клетки трижды промывали натрий-фосфатным буфером (PBS) от незахваченных клетками частиц карбоната кальция и окрашивали с помощью флуоресцентного красителя Calcein AM (ThermoFisher, США). Для этого $1 \mu \mathrm{L}$ раствора красителя в концентрации $1 \mathrm{mg} / \mathrm{mL}$ добавляли к $1000 \mu \mathrm{L}$ среды для получения итоговой концентрация красителя $0.001 \mathrm{mg} / \mathrm{mL}$. Далее клетки визуализировали методом КЛСМ с помощью микроскопа Leica TCS SP8 (LeicaMicrosystems, Великобритания).

\section{Оценка интернализации контейнеров с антимикотиком клетками фибробластов}

Эффективность захвата частиц ватерита с различной структурой оболочки, нагруженных антимикотиком и флуоресцентным красителем, изучалась на культуре клеток L929. Культивирование клеток с контейнерами в концентрации 5 и 10 частиц на клетку производилось в течение $8 \mathrm{~h}$. Для визуализации жизнеспособных клеток и оценки эффективности захвата контейнеров были использованы проточный цитофлуориметр с режимом визуализации AmnisImageStream X Mk II (Luminex, США) и КЛСM Leica TCSSP8.

При подготовке клеток к исследованию методом цитометрии культуральный флакон был трижды промыт от незахваченных частиц натрий-фосфатным буфером без добавления ионов $\mathrm{Ca}^{2+}$ и $\mathrm{Mg}^{2+}$ (БиолоТ, Россия), затем клетки были переведены в суспензию с использованием раствора трипсина с добавлением ЭДТА. Далее клетки были окрашены флуоресцентным красителем Calcein AM. Анализ полученных данных был проведен с использованием программного обеспечения IDEAS 6.2 (Luminex, CША). Для оценки количества захваченных клеткой контейнеров был использован инструмент программного обеспечения „Internalization“, предназначенный для выявления флуоресцентномеченных объектов внутри клетки.

При подготовке образцов к исследованию методом КЛСМ была также проведена трехкратная промывка прикрепленных к флакону клеток с последующим их окрашиванием флуоресцентным красителем Calcein AM.

\section{Результаты и обсуждение}

В ходе исследования были получены частицы ватерита размером $0.8 \pm 0.3 \mu \mathrm{m}$, содержащие антимикотик Gf и флуоресцентный краситель TRITC-BSA. Для стабилизации поверхности контейнеров, контроля процесса их деградации, пролонгации высвобождения иммобилизованного препарата, а также с целью изучения влияния оболочки носителей на эффективность их интернализации клетками линии фибробластов мыши L929 на поверхности частиц методом послойной адсорбции была сформирована оболочка из полиэлектролитов и антикоагулянта. СЭМ-изображения сформированных контейнеров представлены на рис. 1. Отсутствие видимых различий в морфологии контейнеров с различной структурой оболочки связано с ее малой толщиной [43].

Для установления оптимальной продолжительности инкубации частиц с клетками фибробластов, обеспечивающей наиболее эффективный захват частиц, была 


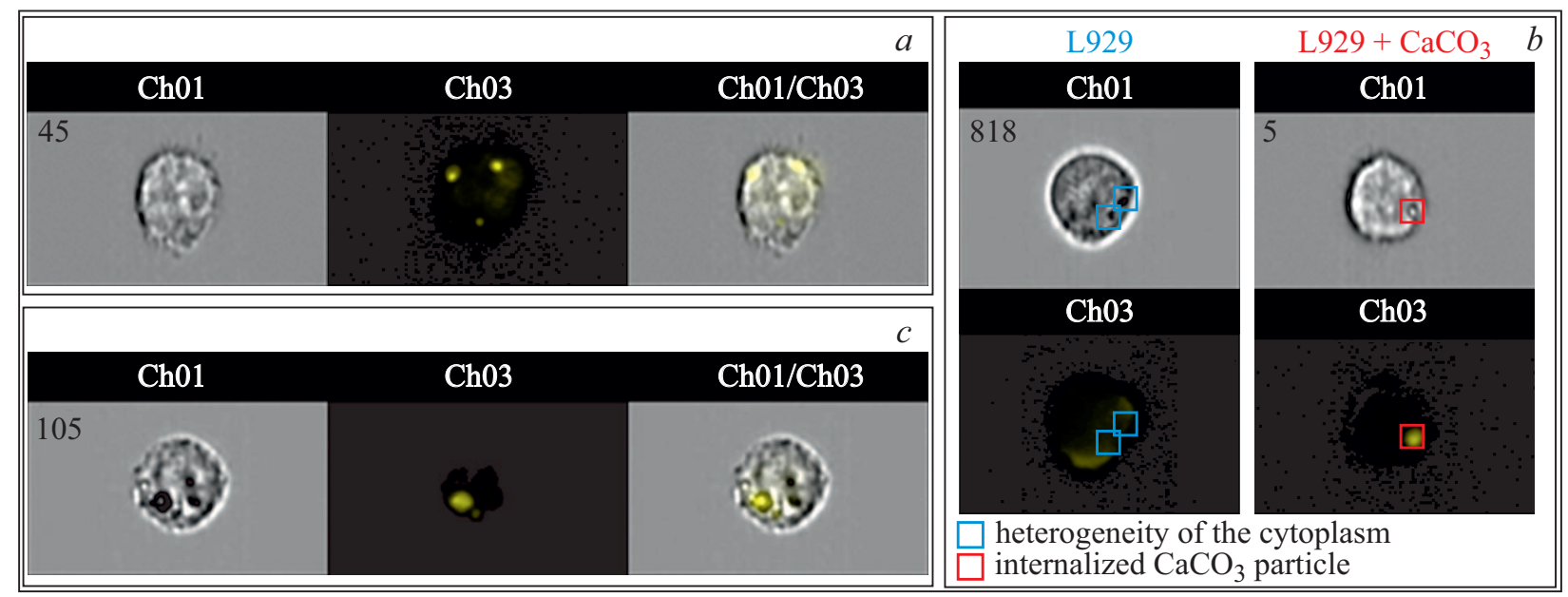

Pис. 3. Светлопольное $(\mathrm{Ch} 01)$ и флуоресцентное $(\mathrm{Ch} 03)$ изображения клеток: захватившей частицы ватерита $(a)$, обладающей неоднородностью цитоплазмы в сравнении с захватившей частицу ватерита $(b)$, содержащей внутри большую частицу кальцита $(c)$.

Таблица 1. Показатели $n_{1}, n_{2}$ и $n_{3}$, характеризующие захват клетками фибробластов ватеритных контейнеров, содержащих антимикотик „Гризеофульвин“ и модифицированных различными типами оболочек: $n_{1}$ - показатель среднего числа частиц, приходящихся на клетку (т.е. отношение количества захваченных частиц к числу клеток, захвативших частицы), рассчитанный для группы клеток, захвативших от 0 до 3 частиц; $n_{2}$ - отношение числа клеток, захвативших частицы, к числу клеток, не захвативших ни одной частицы; $n_{3}$ - отношение числа клеток, захвативших более трех частиц, к числу клеток, захвативших от 0 до 3 частиц

\begin{tabular}{c|c|c|c|c|c|c|c}
\hline \multirow{2}{*}{$n$} & \multicolumn{2}{|c|}{$\mathrm{CaCO}_{3}+\mathrm{Gf}$} & \multicolumn{2}{|c|}{$\left(\mathrm{CaCO}_{3}+\mathrm{Gf}\right) / \mathrm{Hp}$} & $\left(\mathrm{CaCO}_{3}+\mathrm{Gf}\right) /(\mathrm{PArg} / \mathrm{DS})_{2}$ & \multicolumn{2}{c}{$\mathrm{CaCO}{ }_{3}+\mathrm{Gf} /(\mathrm{PArg} / \mathrm{DS})_{2} / \mathrm{Hp}$} \\
\cline { 2 - 8 } & $\begin{array}{c}5 \text { частиц } \\
\text { на клетку }\end{array}$ & $\begin{array}{c}10 \text { частиц } \\
\text { на клетку }\end{array}$ & $\begin{array}{c}5 \text { частиц } \\
\text { на клетку }\end{array}$ & $\begin{array}{c}10 \text { частиц } \\
\text { на клетку }\end{array}$ & $\begin{array}{c}10 \text { частиц } \\
\text { на клетку }\end{array}$ & $\begin{array}{c}5 \text { частиц } \\
\text { на клетку }\end{array}$ & $\begin{array}{c}10 \text { частиц } \\
\text { на клетку }\end{array}$ \\
\hline$n_{1}$ & $0.74 \pm 0.07$ & $0.8 \pm 0.03$ & $0.56 \pm 0.09$ & $0.8 \pm 0.07$ & $1.31 \pm 0.23$ & $0.96 \pm 0.06$ & $1.18 \pm 0.16$ \\
$n_{2}$ & $1.15 \pm 0.12$ & $1.39 \pm 0.32$ & $0.77 \pm 0.16$ & $1.3 \pm 0.08$ & $6.06 \pm 2.37$ & $1.71 \pm 0.3$ & $3.41 \pm 1$ \\
$n_{3}$ & $0.1 \pm 0.02$ & $0.24 \pm 0.09$ & $0.07 \pm 0.02$ & $0.1 \pm 0.01$ & $0.93 \pm 0.09$ & $0.14 \pm 0.3$ & $0.47 \pm 0.04$
\end{tabular}

проведена серия экспериментов. На рис. 2 приведены данные КЛСМ по динамике захвата частиц клетками фибробластов. Зеленый флуоресцентный сигнал в диапазоне 503-540 nm при возбуждении с длиной волны $495 \mathrm{~nm}$ на изображениях соответствует флуоресценции жизнеспособных клеток, окрашенных красителем Calcein AM, красный - флуоресценции маркера TRITCBSA в диапазоне 615-645 nm при возбуждении с длиной волны $552 \mathrm{~nm}$. Фоновое красное свечение (рис. 2,e) обусловлено „хвостом“ эмиссии витального клеточного красителя Calcein AM, перекрывающимся со спектром эмиссии красителя TRITC. Такое перекрытие не позволило нам избавиться от фоновой флуоресценции клеток, прокрашенных Calcein AM, в диапазоне детекции красителя TRITC (615-645 nm). Однако стоит отметить, что это не помешало достоверно идентифицировать контейнеры, меченые TRITC-BSA, поскольку они обладали значительно большей интенсивностью флуоресценции по сравнению с фоновой флуоресценцией клеток.

Было установлено, что в течение $4 \mathrm{~h}$ инкубации частиц с клетками происходит налипание частиц на мембрану без их проникновения внутрь клетки (рис. 2, $b$ ). Таким образом, такая длительность инкубации оказалась недостаточной для прохождения частиц внутрь клетки. 15-часовая инкубация клеток с частицами была признана избыточной (рис. $2, d, g$ ), поскольку за это время частицы не только были захвачены клетками, но также частично деградировали и высвободили иммобилизованное вещество в пространство клетки. Об этом говорит увеличение равномерно излучаемого клетками флуоресцентного сигнала в диапазоне, соответствующем TRITC-BSA (рис. $2, d, g$ ). Высвобождение флуоресцентного красителя затрудняло процесс оценки интернализации.

Оптимальный результат был получен при 8-часовой совместной инкубации частиц и клетками (рис. 2,c). В связи с этим все последующие эксперименты по оценке интернализации методами ВПЦ и КЛСМ были выполнены при инкубации в течение $8 \mathrm{~h}$.

В ходе исследования методом ВПЦ были получены светлопольные изображения исследуемых клеток (канал № 1), а также флуоресцентные изображения частиц ватерита (канал № 3, спектральная ширина канала 560-595 nm), окрашенных TRITC-BSA (возбуждение/эмиссия - 557/576 nm), рис. 3, а. Для проведения измерений использовался лазер с длиной волны $488 \mathrm{~nm}$ при максимальной мощности $200 \mathrm{~mW}$. 


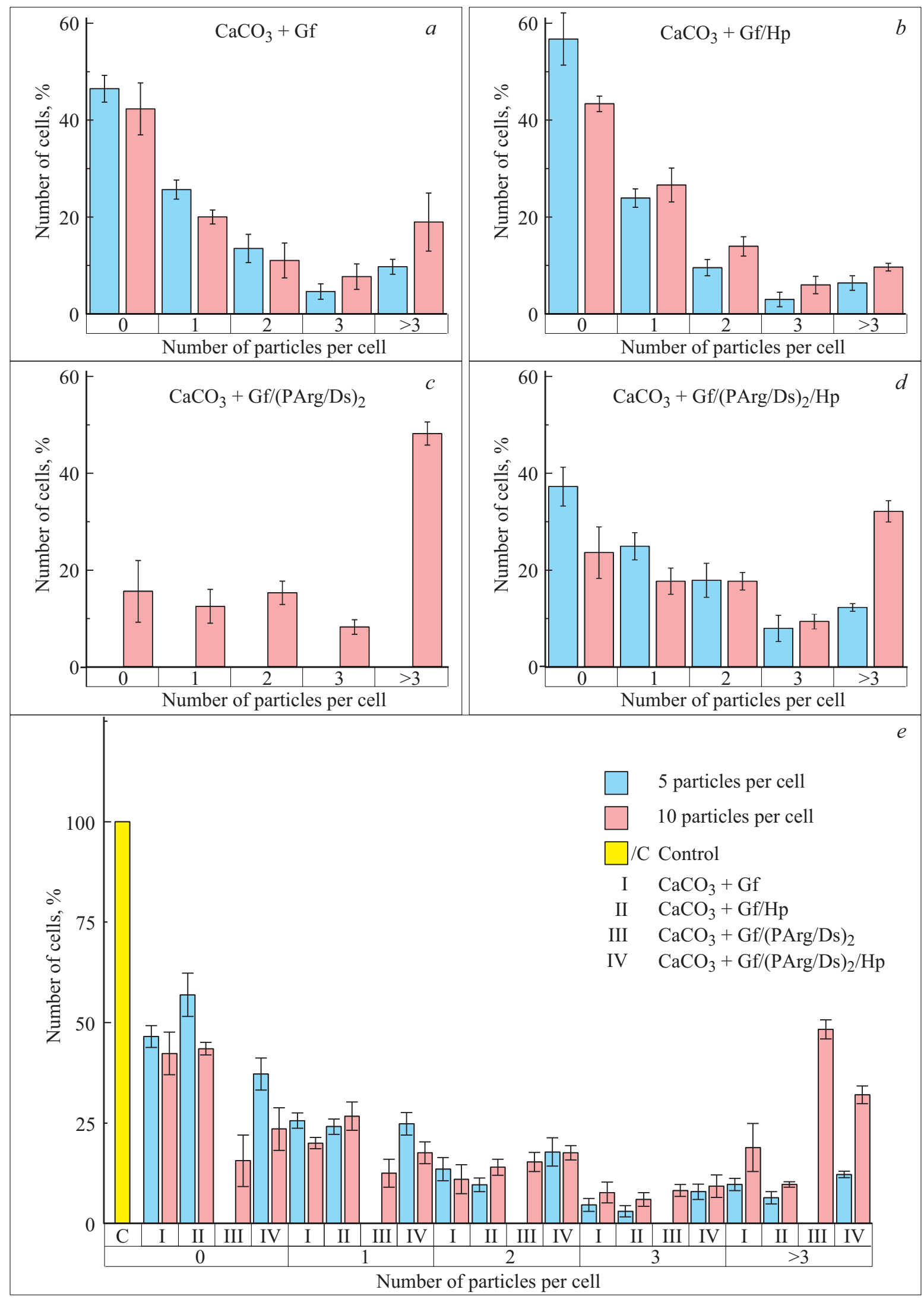

Рис. 4. Процент клеток, захвативших $0,1,2,3$ и более 3 контейнеров после 8 h совместного инкубирования с частицами ватерита $\left(\mathrm{CaCO}_{3}\right)$, содержащих антимикотик „Гризеофульвин“ Gf: без оболочки $(a)$, покрытых слоем гепарина Нр $(b)$, двумя бислоями полиэлектролитов PArg/DS $(c)$, а также двумя бислоями полиэлектролитов и гепарином $(d)$. Общая сравнительная гистограмма $(e)$. 
Таблица 2. Показатели $n_{4}$ и $n_{5}$, характеризующие захват клетками фибробластов ватеритных контейнеров, содержащих антимикотик „Гризеофульвин“ и модифицированных различными типами оболочек: $n_{4}$ - показатель среднего числа частиц, приходящихся на клетку, т. е. отношение общего числа захваченных клетками частиц к общему числу клеток, захвативших частицы; $n_{5}$ - отношение числа клеток, захвативших частицы, к числу клеток, не захвативших ни одной частицы

\begin{tabular}{c|c|c|c|c}
\hline \multirow{2}{*}{$n$} & $\mathrm{CaCO}_{3}+\mathrm{Gf}$ & $\left(\mathrm{CaCO}_{3}+\mathrm{Gf}\right) / \mathrm{Hp}$ & $\left(\mathrm{CaCO}_{3}+\mathrm{Gf}\right) /(\mathrm{PArg} / \mathrm{DS})_{2}$ & $\mathrm{CaCO}_{3}+\mathrm{Gf} /(\mathrm{PArg} / \mathrm{DS})_{2} / \mathrm{Hp}$ \\
\cline { 2 - 5 } & 10 частиц на клетку & 10 частиц на клетку & 10 частиц на клетку & 10 частиц на клетку \\
\hline \multirow{2}{*}{$n_{4}$} & 3.66 & 3.24 & 3.93 & 3.52 \\
$n_{5}$ & 9.69 & 7.75 & 14.67 & 9.77
\end{tabular}

В результате анализа светлопольных и флуоресцентных изображений клеток контрольного образца (без добавления частиц) было установлено, что клетки линии L929 обладают неоднородностью и полидисперсностью цитоплазмы (рис. $3, b$ ), что ограничивало возможность использования светлопольных изображений для оценки интернализации. Во избежание получения ложных результатов анализ захвата контейнеров был проведен с использованием исключительно флуоресцентных изображений клеток. Для удобства оценки интернализации было выделено пять групп: (1) клетки, не захватившие ни одной частицы, (2) клетки, захватившие одну частицу, (3) клетки, захватившие две частицы, (4) клетки, захватившие три частицы и (5) клетки, захватившие более трех частиц.

Для каждого из образцов были проанализированы следующие показатели:

$n_{1}$ - показатель среднего числа частиц, приходящихся на клетку (т.е. отношение количества захваченных частиц к числу клеток, захвативших частицы), рассчитанный для группы клеток, захвативших от 0 до 3 частиц;

$n_{2}$ - отношение числа клеток, захвативших частицы, к числу клеток, не захвативших ни одной частицы;

$n_{3}$ - отношение числа клеток, захвативших более трех частиц, к числу клеток, захвативших от 0 до 3 частиц.

Полученные данные приведены на рис. 4 и в табл. 1 . В ходе анализа полученных данных было выявлено, что частицы ватерита, содержащие антимикотик и флуоресцентный краситель, покрытые полимерной оболочкой без дополнительного покрытия Нр, лучше всего захватывались клетками: отношение числа клеток, захвативших частицы, к „пустым“ клеткам составило $6.06 \pm 2.37$, в то время как для остальных образцов этот показатель в основном колебался в районе единицы. Также для этого образца зафиксировано максимальное среднее число частиц, приходящихся на клетку $-1.31 \pm 0.23$, в то время как для остальных образцов он колебался около 0.8 и за редким исключением не превышал единицы. Последующее нанесение гепарина привело к уменьшению данного отношения почти в 2 раза, а также к снижению показателя числа клеток, захвативших более 3 частиц: 0.14 и 0.47 для 5 и 10 капсул на клетку соответственно против $0.93 \pm 0.09$ для покрытых полимером частиц без гепарина. Таким образом, наличие Нр негативно повлияло на захват частиц клетками. Также было выявлено, что с увеличением числа частиц, приходящихся на клетку, число клеток, не захвативших частицы карбоната кальция, уменьшалось, а количество клеток, захвативших более 3 частиц, увеличивалось в 1.5-3.5 раза в зависимости от образца (рис. $4, e$ ).

Необходимо также отметить, что при инкубации контейнеров, не покрытых полимерной оболочкой, наблюдалось большее количество клеток, не захвативших ни одной частицы - 45-60\% от общего числа клеток, в сравнении с образцами, покрытыми полимерной оболочкой - от 15 до 35\%. Кроме того, клетки, захватившие одну частицу, чаще встречались в результате инкубации с контейнерами без оболочки (рис. $4, e$ ). Это может быть обусловлено тем, что контейнеры, не покрытые полимерной оболочкой, после попадания внутрь клетки быстро высвобождают краситель под действием ферментов. Вследствие этого несколько таких частиц в клетке могут быть приняты за одну ввиду невозможности их отдельного распознавания в полностью окрашенной эндосоме. Также возможно, что частицы, захваченные одной клеткой, с течением времени собираются в одной эндосоме, что увеличивает вероятность их агрегации и перекристаллизации. На это указывает наличие частиц кубической формы (рис. 3,c). В процессе анализа клетки с подобными объектами внутри рассматривались как клетки, захватившие 1 частицу, поскольку достоверно установить, является данный объект результатом перекристаллизации одной или нескольких частиц, невозможно. Нанесение оболочки препятствовало процессу агрегации и перекристаллизации ватеритных контейнеров.

Применение разработанного алгоритма для определения локализации частиц в клетке (в случае достоверности данных) позволяет осуществлять быструю оценку качества эндоцитоза исследуемого образца. Однако используемый алгоритм делает вывод об интернализации объектов, основываясь на фокусе полученных изображений, а применяемая в данном устройстве гидродинамическая фокусировка объектов не исключает возможности их флуктуации в потоке, что значительно снижает прецизионность данного метода. Также короткое время экспозиции объекта в поле зрения камеры не позволяет получить изображение высокого разрешения, что в некоторых случаях затрудняет процесс анализа. В отличие от 

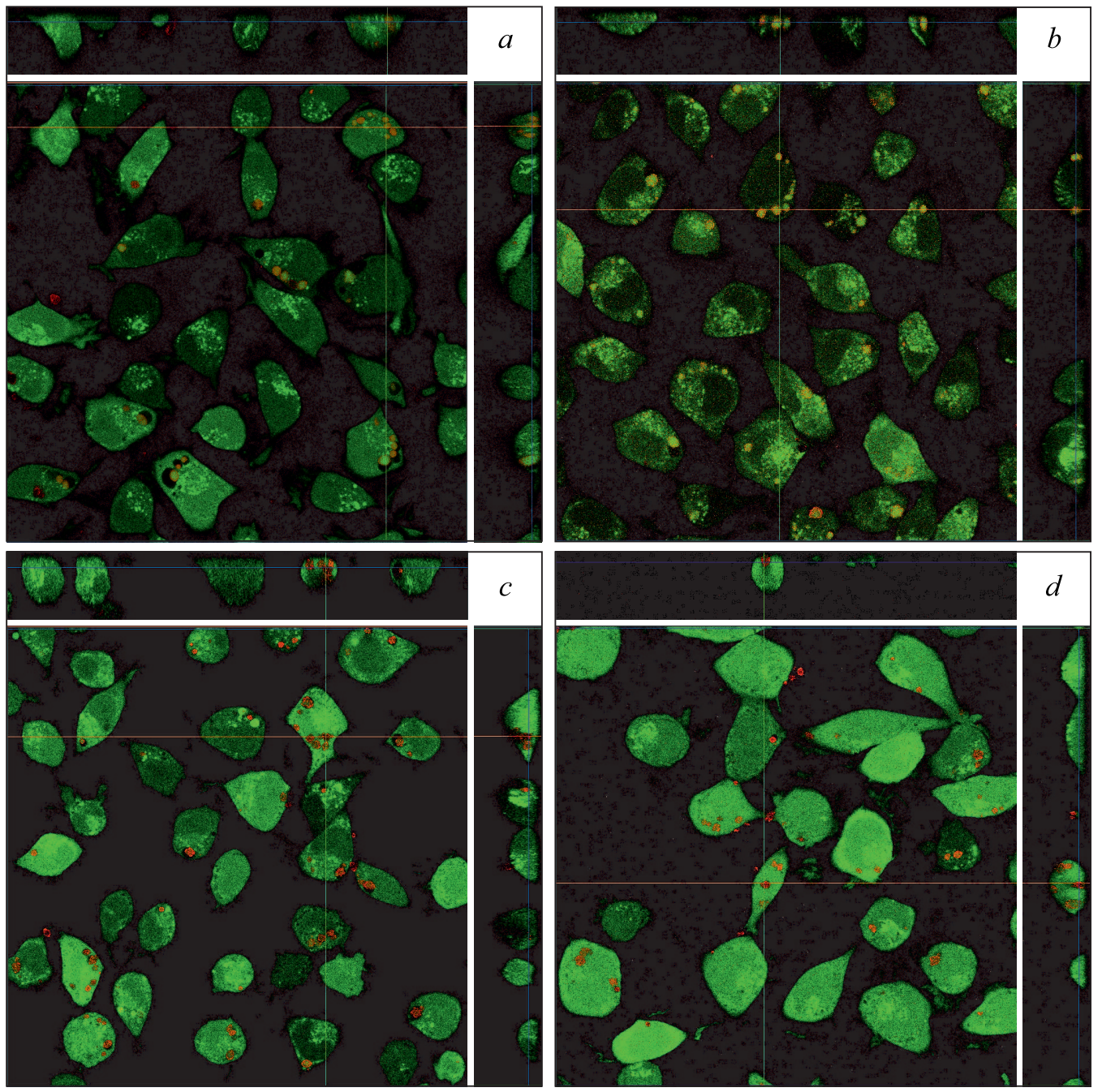

Рис. 5. Конфокальные флуоресцентные изображения клеток дермальных фибробластов L929, инкубированных с различными контейнерами (клетки окрашены красителем Calcein AM, контейнеры - красителем TRITC-BSA), a также ортогональные проекции z-срезов последовательностей оптических срезов (реконструкция трехмерного изображения), демонстрирующие интернализацию контейнеров: частицы $\mathrm{CaCO}_{3}$, загруженные препаратом $\mathrm{Gf}(a)$; $\mathrm{CaCO}_{3}$, загруженные препаратом Gf, покрытые $\mathrm{Hp}(b) ; \mathrm{CaCO}_{3}$, загруженные препаратом Gf, покрытые полиэлектролитными оболочками $(\mathrm{PArg} / \mathrm{DS})_{2}(c) ; \mathrm{CaCO}_{3}$, загруженные препаратом Gf, покрытые (PArg/DS) $)_{2} / \mathrm{Hp}(d)$.

ВПЦ метод КЛСМ более точно определяет положение частицы внутри клетки благодаря возможности сканирования объекта по оси $Z$.

В связи с этим с целью верификации данных, полученных методом ВПЦ, нами было проведено контрольное исследование захвата частиц клетками фибробластов методом КЛСМ. Полученные данные представлены на рис. 5. Зеленый флуоресцентный сигнал на изображениях соответствует флуоресценции жизнеспособных клеток в диапазоне 503-540 nm при возбуждении длиной волны $495 \mathrm{~nm}$, окрашенных красителем Calcein AM, красный - флуоресценции красителя TRITC в диапазоне 615-645 nm при возбуждении длиной волны $552 \mathrm{~nm}$.

По данным, полученным в результате анализа ортогональных проекций $z$-срезов последовательностей оптических срезов (реконструкция трехмерного изобра- жения) для каждого образца, было рассчитано число частиц, содержащихся в клетках. Данные представлены на рис. 6.

Для каждого из образцов были проанализированы следующие показатели:

$n_{4}$ - показатель среднего числа частиц, приходящихся на клетку, т.е. отношение общего числа захваченных клетками частиц к общему числу клеток, захвативших частицы;

$n_{5}$ - отношение числа клеток, захвативших частицы, к числу клеток, не захвативших ни одной частицы.

Полученные данные приведены в табл. 2.

Установлено, что спустя $8 \mathrm{~h}$ инкубации ватеритных контейнеров, содержащих антимикотик и флуоресцентный краситель, с клетками фибробластов L929 наибольшее среднее число частиц, приходящихся на клетку, а также наибольшее отношение клеток, захвативших 

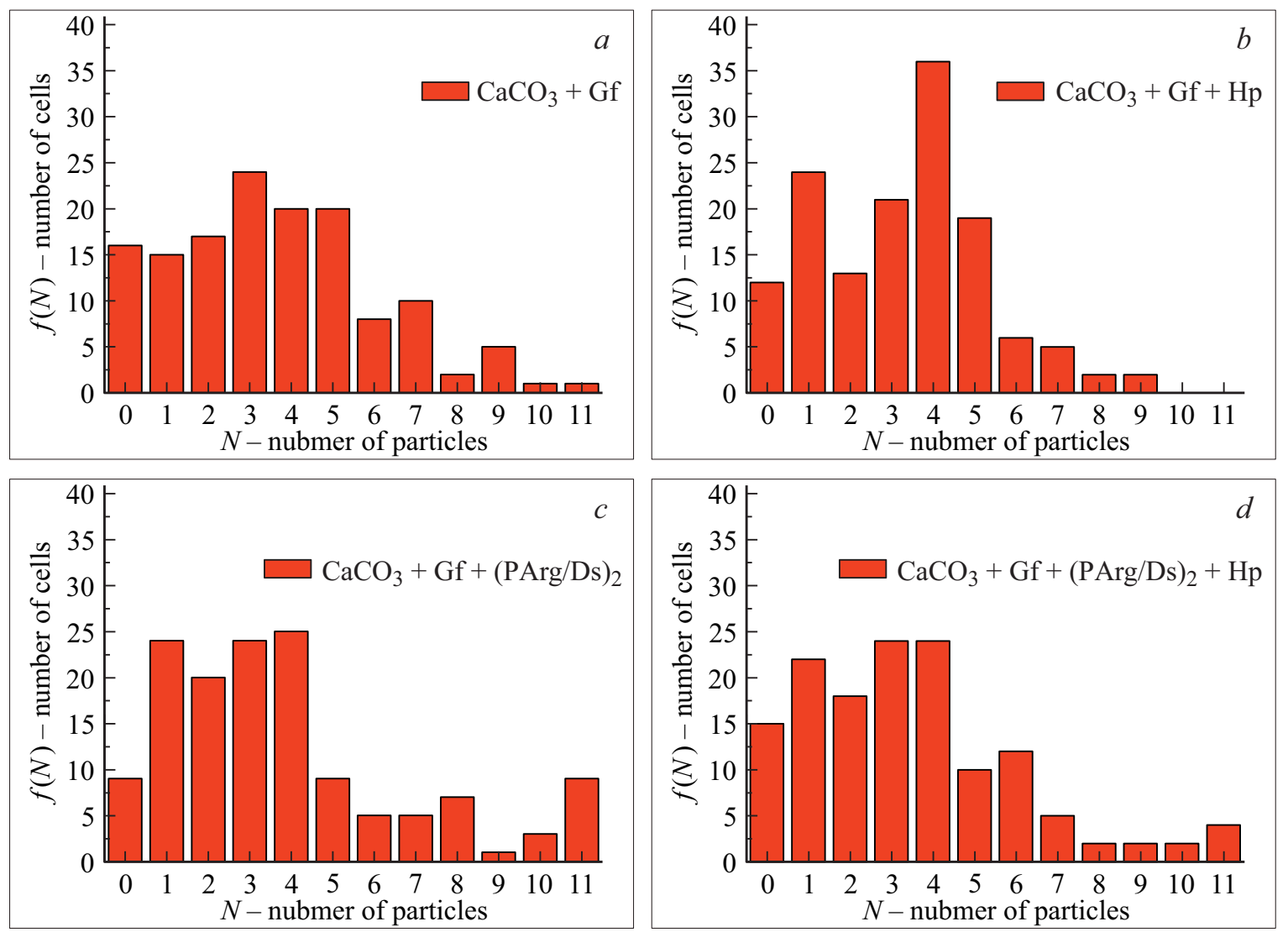

Рис. 6. Функции распределения вероятности захвата контейнеров клетками линии L929, иллюстрирующие число клеток, захвативших от 1 до 11 частиц $\mathrm{CaCO}_{3}$, содержащих Gf: немодифицированных полиэлектролитами $(a)$, покрытых Нр $(b)$, покрытых полиэлектролитами $(\mathrm{PArg} / \mathrm{DS})_{2}(c)$, покрытых $(\mathrm{PArg} / \mathrm{DS})_{2} / \mathrm{Hp}(d)$.

частицы, к пустым соответствовало образцу с полиэлектролитной оболочкой, не покрытой Нр. Нанесение Нр ухудшало захват частиц клетками фибробластов как для частиц, покрытых оболочкой, так и частиц без оболочки. Полученные данные согласуются с данными, полученными методом ВПЦ.

\section{Выводы}

В ходе сравнительного исследования двух подходов к оценке интернализации было установлено, что данные, полученные методом КЛСМ, и данные, полученные методом ВПЦ, для исследованной линии образцов продемонстрировали отличную корреляцию. Выявленные тенденции имеют общий характер, что говорит о возможности применения ВПЦ для быстрого анализа качества интернализации объектов. Оценка количества захваченных частиц методом цитометрии оказалась заниженной, что объясняется худшим качеством изображений, полученных методом ВПЦ, и, как следствие, худшим разрешением частиц внутри клеток по сравнению с исследованием, выполненным на конфокальном микроскопе. Однако метод ВПЦ позволяет за короткий промежуток времени получить большой массив данных, необходимый для статистического анализа, а в сочетании с методом конфокальной микроскопии дает исчерпывающую информацию о захвате носителей клетками различных линий.

\section{Финансирование работы}

Исследование выполнено за счет средств гранта Российского научного фонда (проект № 17-73-20172).

\section{Конфликт интересов}

Авторы заявляют, что у них нет конфликта интересов.

\section{Список литературы}

[1] Decherchi P., Cochard P., Gauthier P. // J. Neurosci. Methods. 1997. V. 71. N 2. P. 205. doi 10.1016/S0165-0270(96)00146-X

[2] Jones K.H., Senft J.A. // J. Histochem. Cytochem. 1985. V. 33. N 1. P. 77. doi $10.1177 / 33.1 .2578146$

[3] Tennant J.R. // Transplantation. 1964. V. 2. N 6. P. 685. doi 10.1097/00007890- 196411000-00001

[4] Stockert J.C., Blázquez-Castro A., Cañete M., Horobin R.W., Villanueva Á. // Acta Histochem. 2012. V. 114. N 8. P. 785. doi 10.1016/j.acthis.2012.01.006 
[5] Rampersad S.N. // Sensors. 2012. V. 12. N 9. P. 12347. doi 10.3390/s120912347

[6] Konopacka-Eyskawa D. // Crystals. 2019. V. 9. N 4. P. 223. doi 10.3390/cryst9040223

[7] Feoktistova N.A., Vikulina A.S., Balabushevich N.G., Skirtach A.G., Volodkin D. // Mater. Des. 2020. V. 185. P. 108223. doi 10.1016/j.matdes.2019.108223

[8] Balabushevich N.G., Lopez de Guerenu A. V., Feoktistova N.A., Skirtach A.G., Volodkin D. // Macromol. Biosci. 2016. V. 16. N 1. P. 95. doi 10.1002/mabi.201500243

[9] Roth R., Schoelkopf J., Huwyler J., Puchkov M. // Eur. J. Pharm. Biopharm. 2018. V. 122. P. 96. doi 10.1016/j.ejpb.2017.10.012

[10] Madadlou A., Floury J., Pezennec S., Dupont D. // Food Hydrocoll. 2018. V. 84. P. 38. doi 10.1016/j.foodhyd.2018.05.054

[11] Yanina I.Y., Svenskaya Y.I., Prikhozhdenko E.S., Bratashov D.N., Lomova M.V., Gorin D.A., Sukhorukov G.B., Tuchin V.V. // J. Biophotonics. 2018. V. 11. N 11. P. e201800058. doi $10.1002 /$ jbio. 201800058

[12] Kazakova L.I., Shabarchina L.I., Sukhorukov G.B. // Phys. Chem. Chem. Phys. 2011. V. 13. N 23. P. 11110. doi $10.1039 / \mathrm{c} 1 \mathrm{cp} 20354 \mathrm{a}$

[13] Donatan S., Yashchenok A., Khan N., Parakhonskiy B., Cocquyt M., Pinchasik B.-E., Khalenkow D., Möhwald H., Konrad M., Skirtach A. // ACS Appl. Mater. Interfaces. 2016. V. 8. N 22. P. 14284-14292. doi 10.1021/acsami.6b03492

[14] Chen S., Zhao D., Li F., Zhuo R.-X., Cheng S.-X. // RSC Adv. 2012. V. 2. N 5. P. 1820 . doi $10.1039 / \mathrm{c} 1 \mathrm{ra} 00527 \mathrm{~h}$

[15] Borodina T., Markvicheva E., Kunizhev S., Möhwald H., Sukhorukov G.B., Kreft O. // Macromol. Rapid Commun. 2007. V. 28. N 18-19. P. 1894. doi 10.1002/marc.200700409

[16] Vostrikova A.V., Prikhozhdenko E.S., Mayorova O.A., Goryacheva I.Y., Tarakina N. V., Sukhorukov G.B., Sapelkin A.V. // Sci. Rep. 2018. V. 8. N 1. P. 9394. doi 10.1038/s41598-018-27488-w

[17] Guo S., Yang M., Chen M., Zhang J., Liu K., Ye L., Gu W. // Dalt. Trans. 2015. V. 44. N 17. P. 8232. doi $10.1039 / \mathrm{C} 5 \mathrm{DT} 00837 \mathrm{~A}$

[18] German S.V., Novoselova M.V., Bratashov D.N., Demina P.A., Atkin V.S., Voronin D.V., Khlebtsov B.N., Parakhonskiy B.V., Sukhorukov G.B., Gorin D.A. // Sci. Rep. 2018. V. 8. N 1. P. 17763. doi 10.1038/s41598-018-35846-X

[19] Parakhonskiy B.V., Svenskaya Y.I., Yashchenok A.M., Fattah H.A., Inozemtseva O.A., Tessarolo F., Antolini R., Gorin D.A. // Colloids Surfaces B Biointerfaces. 2014. V. 118. P. 243. doi 10.1016/j.colsurfb.2014.03.053

[20] Sergeeva A., Sergeev R., Lengert E., Zakharevich A., Parakhonskiy B., Gorin D., Sergeev S., Volodkin D. // ACS Appl. Mater. Interfaces. 2015. V. 7. N 38. P. 21315. doi 10.1021/acsami.5b05848

[21] Li M., Wang Y., Zhang Y., Yu J., Ge S., Yan M. // Biosens. Bioelectron. 2014. V. 59. P. 307. doi 10.1016/j.bios.2014.03.072

[22] Stetciura I.Y., Markin A.V., Ponomarev A.N., Yakimansky A.V., Demina T.S., Grandfils C., Volodkin D.V., Gorin D.A. // Langmuir. 2013. V. 29. N 12. P. 4140. doi 10.1021/la305117t

[23] Sudareva N., Suvorova O., Saprykina N., Smirnova N., Bel'tyukov P., Petunov S., Radilov A., Vilesov A. // J. Microencapsul. 2018. V. 35. N 7-8. P. 619. doi 10.1080/02652048.2018.1559247

[24] Kim S.K., Foote M.B., Huang L. // Cancer Lett. 2013. V. 334. N 2. P. 311. doi 10.1016/j.canlet.2012.07.011
[25] Svenskaya Y., Parakhonskiy B., Haase A., Atkin V., Lukyanets E., Gorin D., Antolini R. // Biophys. Chem. 2013. V. 182. P. 11. doi 10.1016/j.bpc.2013.07.006

[26] Qiu N., Yin H., Ji B., Klauke N., Glidle A., Zhang Y., Song H., Cai L., Ma L., Wang G., Chen L., Wang W. // Mater. Sci. Eng. C. 2012. V. 32. N 8. P. 2634. doi 10.1016/j.msec.2012.08.026

[27] Marchenko I., Borodina T., Trushina D., Rassokhina I., Volkova Y., Shirinian V., Zavarzin I., Gogin A., Bukreeva T. // J. Microencapsul. 2018. V. 35. N 7-8. P. 657. doi 10.1080/02652048.2019.1571642

[28] Svenskaya Y.I., Pavlov A.M., Gorin D.A., Gould D.J., Parakhonskiy B.V., Sukhorukov G.B. // Colloids Surfaces B Biointerfaces. 2016. V. 146. P. 171. doi 10.1016/j.colsurfb.2016.05.090

[29] Lengert E., Verkhovskii R., Yurasov N., Genina E., Svenskaya Y. // Mater. Lett. 2019. V. 248. P. 211. doi 10.1016/j.matlet.2019.04.028

[30] Gusliakova O.I., Lengert E.V., Atkin V.S., Tuchin V.V., Svenskaya Y.I. // Opt. Spectrosc. 2019. V. 126. N 5. P. 539. doi 10.1134/S0030400X19050114

[31] Trushina D.B., Borodina T.N., Artemov V.V., Bukreeva T.V.// Tech. Phys. 2018. V. 63. N 9. P. 1345. doi 10.1134/S1063784218090220

[32] Svenskaya Y.I., Genina E.A., Parakhonskiy B.V., Lengert E.V., Talnikova E.E., Terentyuk G.S., Utz S.R., Gorin D.A., Tuchin V.V., Sukhorukov G.B. // ACS Appl. Mater. Interfaces. 2019. V. 11. N 19. P. 17270. doi 10.1021/acsami.9b04305

[33] Parakhonskiy B., Zyuzin M.V., Yashchenok A., CarregalRomero S., Rejman J., Möhwald H., Parak W.J., Skirtach A.G. // J. Nanobiotechnology. 2015. V. 13. N 1. P. 53. doi 10.1186/s12951-015-0111-7

[34] Schmidt S., Uhlig K., Duschl C., Volodkin D. // Acta Biomater. 2014. V. 10. N 3. P. 1423. doi 10.1016/j.actbio.2013.11.011

[35] Kunwar A., Barik A., Mishra B., Rathinasamy K., Pandey R., Priyadarsini K.I. // Biochim. Biophys. Acta-Gen. Subj. 2008. V. 1780. N 4. P. 673. doi 10.1016/j.bbagen.2007.11.016

[36] De Koker S., De Geest B.G., Cuvelier C., Ferdinande L., Deckers W., Hennink W.E., De Smedt S.C., Mertens N. // Adv. Funct. Mater. 2007. V. 17. N 18. P. 3754. doi 10.1002/adfm.200700416

[37] Agard D.A., Sedat J.W. // Nature. 1983. V. 302. N 5910. P. 676. doi $10.1038 / 302676 a 0$

[38] Carlsson K., Danielsson P.E., Liljeborg A., Majlöf L., Lenz R., Åslund N. // Opt. Lett. 1985. V. 10. N 2. P. 53. doi 10.1364/OL.10.000053

[39] German S.V., Novoselova M.V., Bratashov D.N., Demina P.A., Atkin V.S., Voronin D.V., Khlebtsov B.N., Parakhonskiy B.V., Sukhorukov G.B., Gorin D.A. // Sci. Rep. 2018. V. 8. N 1. P. 17763. doi 10.1038/s41598-018-35846-x

[40] Riccardi C., Nicoletti I. // Nat. Protoc. 2006. V. 1. N 3. P. 1458. doi 10.1038/nprot.2006.238

[41] Vranic S., Boggetto N., Contremoulins V., Mornet S., Reinhardt N., Marano F., Baeza-Squiban A., Boland S. // Part. Fibre Toxicol. 2013. V. 10. N 1. P. 2. doi 10.1186/17438977-10-2

[42] Donath E., Sukhorukov G.B., Caruso F., Davis S.A., Möhwald H. // Angew. Chemie Int. Ed. 1998. V. 37. N 16. P. 2201. doi 10.1002/(SICI)1521-3773(19980904)37:16 $<2201:: A I D-A N I E 2201>3.0 . C O ; 2-\mathrm{E}$

[43] Gorin D.A., Portnov S.A., Inozemtseva O.A., Luklinska Z., Yashchenok A.M., Pavlov A.M., Skirtach A.G., Möhwald H., Sukhorukov G.B. // Phys. Chem. Chem. Phys. 2008. V. 10. N 45. P. 6899. doi 10.1039/b809696a 